again fell to $97 \cdot 4^{\circ}$, and for five days ranged between $97.4^{\circ}$ and 98.4 . Then melæna set in again for four days, with sudden rise to over $100^{\circ}$.

CASE 5.-E. S-, a girl of nineteen, had marked typhoid with spots. On the twentieth day the temperature had risen to $105^{\circ}$. On the twenty-second day she passed blood in her motions, which throughout were very frequent. On the twenty-seventh day the temperature had fallen to $99^{\circ}$ in the morning and $100^{\circ}$ in the evening. For the next six days it remained below $99^{\circ}$; in fact, for the last three days it never exceeded $98^{\circ}$. It then rose again, ranging between $99^{\circ}$ and $103^{\circ}$ for nine days, when for two successive evenings it stood at $986^{\circ}$; yet two days afterwards she died.

I could easily supplement these cases, but, unless they be taken as "the exceptions that prove the rule," they must be quite sufficient. In any case they show that an evening temperature of below $99^{\circ}$ for two, or even three, or even five consecutive evenings is no trustworthy indication that real convalescence bas taken place, or that the ulcers are so far healed that there is no danger of recurrent melæna, or that ve may in confidence and with safety give solid food.

It would indeed be a great boon to us if such a rule could be established, though to be of any use as a guide it must be infallible, or it would be obviously pernicious in the extreme. But I can hardly see how we can hope in these cases to be able ever to lay down a fixed rule when all we are dealing with is so variable-the phases of the disease itself, the different idiosyncrasies of patients, and the consequent varieties of ways in which they are secondarily affected by the morbid poison.

It may be true, and would, I believe, be an excellent caution if it were made a rule, that solid food should never be given until the patient's temperature has been normal for two days; though for myself, regarding the immense importance of the point, I would rather let him starve on for three or four more than run the least risk of the grave consequences $I$ have seen follow too great haste in the matter. But to the converse-the rule laid down by Dr. Watham-I far prefer as my guide the experienced judgment which takes in all points, the state of tongue, of skin, of pulse, of bowels, and, perhaps more than either, the general aspect of the patient, as well as the temperature, remembering that two or three days' delas can do no great harm, whilst a few hours' precipitation may prolong the disease for days, or cost the patient his life.

'Victoria-square West, Clifton.

\section{ON THE OPERATION FOR RUPTURE OF THE PERINEUM AND PROLAPSE OF THE WOMB.}

BY JAMES FOWLER, F.S.A., SURGEON TO THE WAKEFIBLD HOSPITAL AND DISPENSARY.

There is a singular description of an ideal labour in the "Summa Theologiæ" of St. Thomas Aquinas, where the parturition of Eve in the garden of Paradise is described with the minuteness of a Flemish painter. The female parts of generation are described as painlessly relaxing on the descent of the bead of the child, to the size of which they exactly accommodate themselves; and then, after the birth, as contracting, with an altogether incomparable elasticity and perfection, to their original and normal state. The apocryphal gospel "De Nativitate Mariæ et de Infantia Salvatoris" describes in like manner how a midwife found and demonstrated the Blessed Virgin to be a virgin after the birth of our Saviour; the foreshadowing of the later doctrine of a virgin immaculate, as innocent and perfect as Eve before the fall, and hence subject to the same conditions as those described by the angelic doctor. To these ideal representations many labours do, as we know, to a greater or less extent approximate; labours in which, as Sir Thomas Browne remarks, the curse which God pronounced upon the female sex is removed; but, as a rule, these charming pictures contrast cruelly with our daily experience.
To say nothing of the comparative difficulty of even ordinary labour; when the vaginal orifice is small and unyielding, the head of the child large or extensively ossified, or the presentation and birth otherwise abnormal, even with the greatest skill and attention, laceration of the perineum is a common accident-in some cases it is inevitable; and lacerations of the whole length of the perineum, even though not involving the rectum, if not, as frequently, a source of distress and misery at once, are at least liable at any time to become so. Besides the inconvenience and discomfort incident to the patient herself, and the prolapsus, rectocele, or cystocele, which are almost sure sooner or later to follow, and which furnish so large a proportion of our hospital cases, the attachments of the constrictor vaginæ and otber muscles of the perineum being torn through, the normal conditions for proper intercourse no longer exist. Accordingly, it is now generally admitted that ruptures of the perineum should be dealt with at once, on the completion of labour, or at least as soon after as practicable. For several years this has been my own practice, and with the best results. I have brought the edges of the wound together by means of deep quill and superficial sutures; kept the bowels confined as long as necessary; Arawn off the urine regularly with a catheter; kept the patient on a water pillow; had the vagina daily washed out with water and disinfectants; and have been rewarded by always having had union follow-a union the strength of which has in several cases been tried by subsequent labour, and remained firm and elastic. A perineum will, I know, sometimes give way in subsequent labour, however carefully repaired. A lady, not at that time a patient of mine, whose perineum was ruptured in her first confinement, was operated upon in London ten weeks afterwards, in consequence of the great suffering which ensued, by one of the most distinguished surgeon-accoucheurs then living; but four years afterwards, notwithstanding every precaution, it gave way during her next labour. I brought the wound together in the usual manner at once, and secured capital union, avoiding in that manner all the inconvenience and trouble she had previously experienced; but there has been no labour since to test the strength of the parts.

A perineum, again, though apparently well repaired and remaining good through after labours, will not always prevent subsequent prolapse of the womb; relaxation of the vagina and ligaments of the womb, perhaps, ensuing long after the operation has been performed. In some cases, possibly, the removal of mucous membrane may not have been as free as it well might have been; in others the union may not have been carried sufficiently high. But from whatever cause the failure of the operation may have arisen, the fact that there has been a failure at all has repeatedly been urged as a practical objection against its performance. It is in order to show, on the other hand, what complete relief may be afforded by a judicious operation, that I give notes of the following case.

J. R-, aged fifty-six, was confined for the fourth and last time eighteen years ago. She had a slow labour. The child was very large, and instruments were sent for; but before they arrived, all was over naturally. She felt afterwards unusual pain and tenderness of the perineum, and had much scalding in making water. At the end of a fortnight, however, she got up, and did not at once feel much inconvenience. Fourteen years ago she ceased to menstruate. Eight years af terwards she began to have great pain in the back on standing, with occasional bearingdown; and four years later, on lifting a recently filled water-filter, "felt something give way in her inside," and the womb appeared externally. Since then she has been unable to keep it up either with pessaries or any other contrivance. She has had to give up washing; has been unable even to iron a shirt; has not been able to stand during the singing of a bymn in a place of worship; has been unable to walk more than a quarter of a mile at once at the furthest; for weeks together has of ten been unable to get ont of the house at all; has suffered almost constantly from leucorrhoea; has of ten been faint, and sick, and off her food; and, more than all, has had to suffer the domestic misery and distress arising from such a state of things.

Such was her history when she came into our hospital on the 3rd of April, 1871. Her countenance was blanched and expressive of great anxiety. On making an examination. 
the womb was found extensively prolapsed; there was an ulcer, about as large as a shilling, on the os; there was a great deal of leucorrhœa; and the perineum was ruptured backwards as far as the verge of the anus.

Having been placed under the influence of chloroform, in the position for lithotomy, the sides of the fissure were completely denuded from the point where the posterior commissure of the vulva should naturally exist, backwards and upwards towards the rectum, which was next freely denuded in like manner. Immediately in front of the rectum the denudation was carried somewhat higher than usual, in order to produce a certain amount of subsequent contraction of the vagina, and thus prevent the redescent of the womb. Having waited patiently now for some time, and applied ice until the bleeding had entirely ceased, two strong waxed-silk sutures were inserted by means of a long curved needle, and firmly tied on quills on either side the wound, for deep union; and three of stout silver wire, for superficial union of the edges of the skin along the middle line of the perineum. On passing the forefinger into the vagina, apposition of the two sides of the fissure was found to be complete.

Placed on her left side on a water cushion, with the knees tied together and flexed on the abdomen, the treatment was the same as after operations generally, except that, in addition, the bowels were confined with opium, the urine regularly drawn off every six hours with a catheter, and the vagina washed out every day with a stream of warm water and Condy's finid. I have no regular time for removing the sutures, but in this particular case the deep ones were taken out ninety hours, and the superficial ones a hundred hours after the operation. Union was found to be complete and firm. On the seventh day the bowels were relieved by castor oil and an enema, so as to cause as little disturbance of the new perineum as possible. In order to avoid any possible strain, and to allow the swollen and ulcerated womb to recover its normal condition, and its relaxed ligaments to strengthen, bed was enjoined for three weeks Ionger; and at the end of the month she drove howe in a cab.

Fur a long time she could not believe that she was really cured, but gradually felt her way about her housebold duties. The womb bas never been down since, nor bas she ever bad the slightest feeling of pain or inconvenience. She can wash a fortnight's wash and iron and clean for a family of four regularly now without assistance, fetching and carrying water, emptying the tubs, \&c., all by berself. She also walks to Wakefield every week in the middle of the day to market-a distance of four miles, does her shop. ping, and then was back again in the evening, without the slightest feeling of local weakness; and gets along faster than one of her years and figure (ratber stout) might be expected to do. She can also stand quite comfortably for any length of time. Her general bealth is as good as possible, and she has never had any leucorrbod since she left the hospital, now more than two years ago.

By an operation of this kind it must be admitted therefore that the evils of a torn perineum may be completely remedied. If not raised to an ideally perfect condition, the perineum thus treated is at least brought back to the state in which it was before the accident, which is sufficient -at least in the great majurity of cases-for all practical purposes.

South-parade, Wakefield.

The adulteration of Food Act in St. Parcras. -Dr. Stevenson, medical officer of health and analpst, has presented to the St. Pancras Vestry his second quarterly report, in which he states that be has analysed seventynine articles of food and drink. In none of the samples of butter was he able to detect any adulteration; some were, bowever, unduly salted, some were very watery, and in many cases the quality was inferior and the articles rancid. Samples of mill were found to be watered, and in three cases prcsecutions were instituted, and fines of $£ 10$, \&5, and $5 s$. and costs were respectively iuflicted. He frequently hears encomiums upon the vestry for having procured better milk-supply. Buth the samples of tea analysed were admixed with leaves otber than tea-leaves, though to no great extent. All the samples of coffee were found to be genuine. Every sample of cocoa was largely admixed with cane-sugar and other matters, chiefly sago.

\section{d a dittror}

\section{H O S P T A L P A C T I E,}

\author{
BRITISH AND FOREIGN.
}

Nulla autem est alia pro certo noscendi via, nisi quamplurimas et morborura et dissectionum historias, tum aliorum, tum proprias collectas habere, et inter se comparare.-Mongag I De Sed.et Caus. Morb., lib. iv. Procmium.

\section{UNIVERSITY COLLEGE HOSPITAL.}

FOUR CASES OF EPITHELIOMA OF THE TONGUE; REMOVAL BY THE GALVANO-ECRASEUR.

Tue following is a continuation of the report of the cases from the last volume, page 803 . The association of the outbreak of the disease and local irritation is well illustrated in the subjoined cases: where, in one case, the growth seemed to have commenced from an injury of the tongue inflicted by a tobacco-pipe; in the other, the growth commenced in a part that had been previously exposed to the irritating action of the roughened edge of a decayed tooth. Such an association should not, however, always be regarded as essential; for it is possible that the presence of a local irritant may only have been the means of directing early attention to the part already advanced in disease.

CASE 3. Epithelioma of the tongue; removal; relief. (Under the care of Mr. ERICHSEN.) - Henry A-, a cooper's smith, aged forty-six, was admitted on Jan. 21st, 1873. The patient had always enjoyed good health; never had syphilis; and his family history was good. On admission, there was on the left dorsum of the tongue an vlcer of the size of a shilling, with a sloughy centre, hard everted edges, and an indurated base, extending deeply into the substance of the organ as far back as the circumvallate papillæ. The patient stated that the ulcer had been forming about three months, and was caused in the first instance through wounding the tongue by falling against a door with his pipe in his mouth. There were no decayed teeth on this side of the jaw. The lymphatic glands on the left side, under the angle of the jaw and down the edge of the sterno-mastoid muscle, were enlarged, and there was a distinct blue line on the gums.

On Jan. 29th the tongue was removed in the following manner :-The patient having been put under the influence of chloroform, a pair of ring forceps with an elastic band over the baudles to keep the blades together was made to clasp the cheek about a quarter of an inch below and outside the commissure of the mouth, in order to secure the lower branch of the coronary artery. An incision was then carried through the substance of the cheek as far as the anterior border of the masseter muscle, in a line with the level of the teeth in the upper jaw. Several arteries required to be ligatured. 'I'he frenum and the muscles of the tongue that are attached to the lower jaw behind the symphysis were next divided, the tongue drawn well forwards, and a wire passed through its base close in front of the byoid bone in the median line. The wire was then connected with a galvanic apparatus, and made to cut forwards through the median line. The left side of the tongue was finally removed by cutting through the base with a loop of the wire. No hæmorrhage occurred during the performance of this part of the operation. The lips of the wound in the cheek were next closely adjusted and secured by means of harelip pins. A microscopic examination of the tumour revealed the characters of lobulated epithelioma. A nutritive enema, consisting of beef-tea and egg and pepsin and hydrochloric acid, previously warmed for half an hour, was given every four hours, and the mouth was frequently washed out with weak Condy's fluid.

The progress was very satisfactory for several days, but suppuration subsequently took place in the left eyelid and temporal region. The wound in the cheek united by first intention except at the posterior part, which became the seat of exuberant granulations, but these soon disappeared af ter the removal of a knot of a ligature on Feb. 27 th.

March 8th.-Patient discharged. To attend as an outpatient. 